\title{
A New Year Message from Chinese Science Bulletin
}

The year 2009 is the 60th anniversary of the founding of the People's Republic of China, and it is also the 60th founding anniversary of the Chinese Academy of Sciences (CAS). In the magnificent 60 years of development, scientists and technicians all over the country have achieved great successes through their hard work.

On the 60th founding anniversary of the CAS, Chinese President Hu Jintao has written a congratulatory letter to the CAS; State Councilor Liu Yandong made an important speech. This fully reflects that the central government attaches great importance to, shows warm concern for, and places high hopes on the scientists and technicians all over China. In their letter and speech, they, on the one hand, fully affirmed the outstanding achievements made by the CAS over the past 60 years, on the other hand, they laid new hopes and set stricter demands on the future development of the CAS and Chinese scientific and technological circles from the aspects of strategy and an overall situation.

President Hu Jintao pointed out in his congratulatory letter that "In the world today, there is fraught with a new turn of tremendous new ideas and breakthroughs as well as revolutionary changes in the field of science and technology, and all the countries in the world attach more importance to the utilization of the force of science and technology to seize the vantage point for future development." State Councilor Liu Yandong indicated in her speech that "Basic research is the knowledge foundation for the objective law of human cognition. It is also the source of initiative creation; therefore, it has far-reaching influence on and inestimable infiltrating forces to the development of science and the actual productive forces. And $90 \%$ of the technical achievements today come from basic research and creation". "At present, there is still some gap between the overall strength of the basic research of our country and that of the world advanced level. There are few tremendous original creative achievements in our country. But, we are already at the important stage where the accumulation could be advanced to a qualitative change, and therefore, we are fully qualified for the new breakthrough and development."

Chinese Science Bulletin is one of the main academic publications for basic research of our country. In the year 2010 , all the members of the editorial board make a resolve to offer top-notch service for scientists and technicians all over the country, and to give timely and prior publication of their original achievements obtained in every field of basic research in order to promote national and international academic exchanges.

The Chinese edition of Chinese Science Bulletin started publication in 1950, and its English edition, in 1966, and therefore, this year is the 60th anniversary of starting publication of the Chinese edition. It grows up with New China, witnesses the developent process from nil to prosperity of science and technology of New China, and also witnesses the development of scientists one generation after another. With the vigorous development of the Chinese science and technology, the present semimonthly publication can not meet the demands for the authors to promptly publish their excellent original scientific achievements. Proposed by the editorial department and approved by the department at the higher level, both the Chinese edition and the English edition of Chinese Science Bulletin will be published once every ten days from the year 2010 , so as to offer much space for publication.

The success of an academic publication will depend on the concern and support of its authors, i.e. scientists and technicians. We hope that in the year 2010 we can receive more and better manuscripts by you, and get more and valuable suggestions from you. Let us try our best to make Chinese Science Bulletin a window on the achievements of basic research of our country, as well as on international exchanges, and make contributions to the seizing of the vantage point of the new turn of scientific and technological revolution.

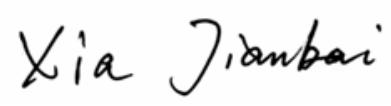

Editor-in-Chief

(Institute of Semiconductor, Chinese Academy of Sciences, Beijing 100083, China) 